\title{
Questões energéticas e suas relações com parâmetros CTS: análise em livros didáticos a partir de uma matriz de referência
}

Energy issues and their relationship with STS parameters: analysis in textbooks from a reference matrix

Marcia Santos e Silva ${ }^{1}$

Suiane Ewerling da Rosa²

\section{Resumo}

A educação Ciência-Tecnologia-Sociedade (CTS) tem como um dos seus objetivos a proposição educacional em torno de temas sociais de ciência e tecnologia, a partir de uma abordagem interdisciplinar e contextualizada, alinhada a processos de democratização. Neste sentido, buscamos investigar de que maneira esse propósito é proporcionado e potencializado nos livros didáticos. Considerando uma pesquisa qualitativa e bibliográfica, temos como objetivo analisar livros didáticos de Física tendo como pano de fundo uma matriz de referência CTS. Como base teórica para este trabalho nos fundamentamos em referenciais da educação CTS e suas articulações com os pressupostos teórico-filosóficos de Paulo Freire e do Pensamento LatinoAmericano em CTS. Como resultado destacamos aspectos limitadores e potencializadores referentes ao objetivo em questão, sendo que, de maneira geral, os parâmetros CTS são apresentados pontualmente e sem problematizações profundas, evidenciando, portanto, desafios para a área.

Palavras chave: ensino de ciências; CTS; livro didático.

\section{Abstract}

The Science-Technology-Society (STS) education has as one objective the educational proposition around social themes of science and technology, from an interdisciplinary and contextualized approach, aligned with democratization processes. In this sense, we seek to investigate how this purpose is provided and enhanced in textbooks. Considering a qualitative and bibliographical research, we aim to analyze Physics textbooks against the backdrop of a STS reference matrix. As a theoretical basis for this work, we are based on references of STS education and its articulations with the theoretical-philosophical assumptions of Paulo Freire and Latin American Thought on STS. As a result, we highlight limiting and enhancing aspects related to the objective in question, and, in general, the STS parameters are presented punctually and without deep problematization, thus evidencing challenges for the area.

Keywords: science teaching; STS; textbook.

\footnotetext{
${ }^{1}$ Universidade Federal do Oeste da Bahia | marcia.silva@ufob.edu.br

${ }^{2}$ Universidade Federal do Oeste da Bahia|suiane.rosa@ufob.edu.br
} 


\section{Introdução}

Diferentes pesquisadores do Ensino de Ciências/Física têm apontado diversos desafios vivenciados pela área. Dentre os desafios, têm aqueles que são mais antigos e que são anunciados desde a década de cinquenta/sessenta e que se relacionam, principalmente, com situações que envolvem processos de ensino-aprendizagem, até os mais recentes e que incluem discussões sobre redirecionamentos dos currículos e práticas educativas frente as demandas do mundo contemporâneo (MOREIRA, 2018; 2021; SOUZA, 2012).

Referente ao Ensino de Física, Moreira (2021) ressalta que, em geral nos contextos educacionais, não há uma abordagem significativa dos objetos de conhecimento da área, pois os estudantes "memorizam mecanicamente fórmulas, definições, respostas certas, para serem reproduzidas nas provas e esquecidas logo depois" (p. 1). Para este autor e para Auler (2007), vivenciamos uma cultura escolar de testagem, de treinamento para as etapas futuras, seja para passar de ano, para fazer uma prova ou ainda uma preparação para o mercado de trabalho. As críticas à concepção propedêutica de educação situam-se no fato da anulação do tempo presente, em que a satisfação do tempo e vivência escolar são jogadas, sempre, para o futuro, do que a porvir. No entanto, reflexos dessa concepção são comuns e vivenciadas a todo momento no espaço escolar, pois quando os estudantes não encontram motivação e interesse na escola, em outras palavras, quando há ausência de sentido ao que se faz lá, as consequências são imediatas: desmotivação, evasão, indisciplina, desinteresse, insatisfação entre outros aspectos (AULER, 2007). Por outro lado, o que se busca é um espaço-tempo escolar de significação, de vivência, de alegria, de realizações e criticidade, porém: como promover, construir e dinamizar práticas educativas para o Ensino de Ciências/Física alinhadas a essa perspectiva? Que pressupostos teórico-práticos têm contribuído para esse alcance?

Para Hunsche (2010), a busca por essas transformações se relaciona, dentre outras questões, com a própria participação dos professores na construção dos currículos escolares, isso porque o currículo concebido apenas por uma listagem de conteúdos científicos descontextualizados a serem "vencidos" ao longo do calendário letivo, perspectiva que alimenta a concepção propedêutica, são insuficientes e desmotivadores num processo de relevância e transformação educacional. Defende-se que a realidade vivenciada pelos estudantes, articulada com problemas/temas do mundo contemporâneo, sejam considerados ponto de partida para a construção e redirecionamentos dos currículos, práticas e materiais educativos. Para além disso, os professores precisam assumir o papel de construtores críticos de ações educativas, e não apenas reprodutores/executores de um currículo e materiais engessados e desarticulados com as demandas sociais e educacionais.

Corroborando com essa perspectiva, Auler (2007) destaca redimensionamentos possíveis para se (re)pensar propósitos críticos do Ensino de Ciências/Física. Para ele, devemos priorizar ações educativas que articulem o "mundo da vida" e o "mundo da escola", pois para despertar a curiosidade, a criticidade, o interesse pela cultura escolar e a busca pela participação ativa dos sujeitos em temas/problemas reais e contemporâneos vivenciados, esses dois mundos não podem estar desarticulados.

Dessa forma, fundamentado pelos autores mencionados, vivemos um tempo que é necessário reinventar a escola, o currículo, as práticas e o tempo presente neles. Ou seja, é preciso superar o modelo propedêutico, de testagem, de mecanização, de aprender para posteriormente participar, em busca de uma cultura participativa/ativa e crítica, de aprender participando, conforme postulado por Freire (2005). No entanto, essa perspectiva 
educacional torna-se possível quando o ato educativo, as práticas e materiais de ensino possuem significado e relevância, quando estes, conforme já exposto, se constituem da própria realidade vivenciada pelos estudantes. Diante disso, diversos grupos de pesquisas em Educação em Ciências, no contexto nacional, vêm desenvolvendo pesquisas que têm como propósito evidenciar possibilidades para práticas curriculares e educativas em torno dos desafios anteriormente mencionados. Neste contexto, destacamos as balizadas pelos referenciais de Paulo Freire e da educação Ciência-Tecnologia-Sociedade (CTS), pois, para Auler (2002), a articulação desses referenciais implica na busca por uma leitura crítica da realidade, marcada cada vez mais por um contexto científico-tecnológico. Dessa forma, há a necessidade da constituição de sujeitos que problematizem e atuem em temas sociais que envolvem ciência e tecnologia. Aspecto que, a nosso ver, se torna inviável com os currículos hegemônicos. Assim, Auler (2007), fundamentado pelas aproximações de Freire-CTS, propõe como possibilidade a construção de currículos e práticas fundamentadas em torno de temas sociais de ciência e tecnologia, de uma abordagem interdisciplinar e que possibilitem a construção de processos democráticos.

Portanto, com o intuito de contribuir com essas demandas, buscamos propor encaminhamentos a partir de uma investigação orientada por referenciais que almejam uma maior democratização da sociedade, da educação, de ciência e tecnologia, como as defendias pelas aproximações Freire-CTS. Diante desse propósito e considerando que os livros/materiais didáticos possuem papel de extrema importância e relevância na construção de currículos e práticas educativas, buscamos investigar a seguinte problematização: como temas que envolvem questões energéticas, presentes em livros didáticos de Física, têm evidenciado o alcance de propósitos CTS?

A escolha por objetos de conhecimentos relacionados a energia se justifica pela relevância desse tema na sociedade e o alcance de discussões potentes e significativas para o Ensino de Ciências/Física, isso porque permite incluir discussões que implicam a matriz energética global e local, investigações sobre as diferentes fontes de energia, estudos e avanços técnico-científicos sobre eficiência, suas relações com aspectos econômicos e sociais, implicações ambientais e de políticas públicas. Assim, por meio de uma pesquisa qualitativa e bibliográfica, buscamos apresentar resultados que indiquem limitações e potencialidades referentes a problematização levantada, sinalizando encaminhamentos para a área, em especial para redirecionamentos curriculares, de práticas e materiais educativos fundamentados por temas sociais que envolvem ciência e tecnologia e que sejam coerentes com os propósitos educacionais mencionados. Dessa forma, apresentaremos a seguir o percurso teórico e metodológico da pesquisa para posteriormente discutir os resultados obtidos.

\section{Encaminhamentos teórico-metodológicos}

CTS, como movimento social amplo, nasce com o propósito de estabelecer um olhar mais crítico frente ao desenvolvimento científico-tecnológico na sociedade. Essa iniciativa surge após a segunda guerra mundial devido ao descontentamento com as consequências causadas pelo suposto progresso científico como, por exemplo, as bombas atômicas (AULER; BAZZO, 2001). Referente à origem do movimento, Garcia, Cerezo e López (1996) ainda destacam duas obras que têm sido consideradas provocadoras desse surgimento, que são: A Estrutura das Revoluções Científicas, do filósofo e físico Thomas Kuhn, com 
problematizações referentes ao papel sócio-histórico do desenvolvimento científico; e o livro Primavera Silenciosa, lançado pela bióloga e ativista Rachel Carson em setembro de 1962, que denunciava o desaparecimento de pássaros devido ao uso do DDT (diclorodifenil-tricloroetano). Essas publicações, com origem e propósitos diferentes, potencializaram as discussões sobre as interações entre CTS, e por isso tem sido considerados marcos importantes da origem e trajetória desse movimento.

Diferentemente da tradição que nasce no hemisfério Norte, no contexto da América Latina tem-se a vertente denominada de Pensamento Latino-Americano em CTS (PLACTS). Essa tradição tem na sua gênese questionamentos que vão além das implicações e consequências do desenvolvimento científico-tecnológico, propósito marcante nos movimentos do Norte, para problematizar o modelo de ciência e tecnologia adotado pelos países latino-americanos. Assim, o PLACTS parte da ideia de que o modelo adotado localmente é espelhado em nações que estão em um contexto social e econômico diferente do nosso, portanto deixa-se à mercê as realidades regionais e locais e as implicações que a adoção indiscriminada desse modelo pode acarretar (STRIEDER; KAWAMURA, 2017). Corroborando com essas discussões, Auler e Bazzo (2001) apontam para "a necessidade de outras formas de tecnologia. A alternativa não consiste em "mais C\&T", mas "num tipo diferente de C\&T", concebidas com alguma participação da sociedade (p. 2). Ou seja, um dos propósitos almejado pelos seguidores do PLACTS estava na busca por uma política de ciência e tecnologia que considerasse as demandas da realidade local, fazendo dela "um objeto de estudo público, um tópico ligado à estratégias de desenvolvimento social e econômico" (VON LINSINGEN, 2007, p. 7).

Conforme apresentado, o movimento CTS surge em um primeiro momento no contexto acadêmico e no âmbito dos movimentos sociais, e somente mais tarde repercute no campo educacional tendo como propósito o desenvolvimento de ações educativas voltadas para uma formação política, organizadas a partir de temas sociais de ciência e tecnologia com enfoque interdisciplinar, objetivando a constituição de sujeitos críticos e participativos em processos decisórios sobre esses temas (AULER, 2011; GARCÍA; CEREZO; LÓPEZ 1996; SANTOS, 2012; SOUZA, 2012; STRIEDER; KAWAMURA, 2017). Especificamente no Brasil, essa repercussão aconteceu, principalmente e mais fortemente, no início da década de noventa. Época em que a educação brasileira passou, também, por grandes reformas educacionais como a promulgação da Lei de Diretrizes e Bases da Educação e, a partir dela, a aprovação de outros documentos oficiais com indicativos coerentes com os pressupostos CTS. De maneira geral, esses documentos recomendam a formação para o exercício da cidadania, posicionamento crítico frente às implicações e uso da ciência e tecnologia, desenvolvimento argumentativo, entendimento sobre ciência e tecnologia como construção sócio-histórica e contribuições para uma participação ativa dos estudantes (ROSA, 2019; RIBAS; BROIETTI, 2020). Em especial, no Edital de Convocação para o Processo de Inscrição e Avaliação de Obras Didáticas para o PNLD (Programa Nacional do Livro e do Material Didático), do ano de 2018, há recomendações com relação à educação CTS. Nesse sentido, referente ao item "Critérios eliminatórios específicos para o componente curricular Física" há a menção sobre o fato de se a obra:

[...] propõe discussões sobre as relações entre ciência, tecnologia, sociedade e ambiente, promovendo a formação de um cidadão capaz de apreciar e de posicionar-se criticamente diante das contribuições e dos 
impactos da ciência e da tecnologia sobre a vida social e individual (BRASIL, 2015, p. 57).

Considerando que o livro didático constitui um dos principais instrumentos de trabalho e planejamento de propostas educativas do professor e que diferentes pesquisas têm evidenciado a presença dos pressupostos CTS nos documentos oficiais brasileiros, como o PNLD, é válido investigar a presença, as potencialidades e limitações nos livros didáticos da área de Física aprovados nessa política pública a partir de propósitos e pressupostos educacionais CTS. É válido destacar que somente a partir do ano de 2004 que esse programa passa a considerar a etapa do ensino médio, incluindo, dessa maneira, os livros didáticos de Física, possibilitando o amplo acesso dos livros e materiais didáticos para os estudantes da educação básica e o aumento da sua qualidade (BRASIL, 2019).

Além do exposto, é importante destacar que a educação CTS tem assumido, conforme Strieder (2012) e Strieder e Kawamura (2017), diferentes propósitos, significados e repercussões educacionais desde a sua origem, ou seja, pode-se dizer que CTS constitui-se um campo polissêmico. Assim, visando compreender melhor esse campo, que é crescente no contexto brasileiro, em especial a partir da década de noventa, as autoras realizaram um estudo do estado da arte buscando caracterizar parâmetros e propósitos. Como encaminhamento, as autoras desenvolveram uma matriz de referência situando propósitos educacionais CTS (desenvolvimento de percepções, desenvolvimento de questionamentos e compromisso social) e parâmetros educacionais CTS (racionalidade científica, desenvolvimento tecnológico e participação social) com cincos níveis de criticidade em cada um deles.

Referente aos propósitos, o primeiro se refere a ações educativas que tem como ênfase promover uma aproximação do conteúdo escolar com o contexto dos estudantes. O segundo busca-se promover discussões sobre as implicações da atividade científicotecnológica na sociedade e, por último, o compromisso social está articulado ao desenvolvimento de competências para que a sociedade atue, de forma crítica, sobre os problemas sociais de diferentes naturezas (STRIEDER; KAWAMURA, 2017).

Os parâmetros, que serão aprofundados ao longo dos resultados, pois constituem a referência para a análise dos livros didáticos, caracterizaram-se como: (i) racionalidade científica: que apresenta discussões acerca da construção da ciência, considerando estudos filosóficos sobre o empirismo e métodos científico e àqueles relacionados aos fatores sociais e humanos; (ii) desenvolvimento tecnológico: que se refere à discussões sobre os impactos e direcionamentos do conhecimento tecnológico, problematizando o pensamento salvacionista atribuído a ele, ou seja, a ideia de que o desenvolvimento tecnológico gera desenvolvimento social e, consequentemente, bem-estar social; e (iii) participação social: associado ao desenvolvimento de interações sociais e políticas públicas determinadas não só por cientistas, mas também por diversos grupos sociais que carregam valores diferentes (STRIEDER; KAWAMURA, 2017). A matriz da educação CTS segue parâmetros de diferentes níveis de criticidade. Logo, vai de abordagens de ensino contextual, para influência da ciência e tecnologia na sociedade, até abordagens que buscam a constituição de sujeitos mais reflexivos, críticos e atuantes.

Com o intuito de contribuir para a inserção de discussões críticas sobre CTS em propostas educativas no contexto educacional, especificamente no Ensino de Física, apresentamos este trabalho. Assim, buscamos investigar como os livros didáticos, aprovados no PNLD 2018, estão abordando os diferentes níveis de criticidade referentes aos 
parâmetros da educação CTS, tomando como ênfase os conteúdos e abordagens voltadas para questões energéticas e suas relações com temas socioambientais.

Referente aos livros didáticos da área de Física, corpus da nossa investigação, o PNLD 2018 aprovou doze coleções, totalizando assim trinta e seis livros. No entanto, para a realização deste trabalho, consideramos nove coleções ${ }^{3}$ conforme apresentado no Quadro 1.

Quadro 1. Livros didáticos analisados.

\begin{tabular}{|c|c|c|c|}
\hline$N^{\circ}$ & Livros & Autores & Ano/Edição \\
\hline 1 & Física aula por aula- Mecânica & Barreto e Xavier & $\begin{array}{l}3^{a} \text { edição } \\
\text { SP/2016 }\end{array}$ \\
\hline 2 & $\begin{array}{c}\text { Física aula por aula - Termologia, } \\
\text { Óptica, Ondulatória }\end{array}$ & Barreto e Xavier & $\begin{array}{l}\text { 3a edição } \\
\text { SP/2016 }\end{array}$ \\
\hline 3 & $\begin{array}{l}\text { Física aula por aula - } \\
\text { Eletromagnetismo, Física Moderna }\end{array}$ & Barreto e Xavier & $\begin{array}{l}\text { 3a edição } \\
\text { SP/2016 }\end{array}$ \\
\hline 4 & Física- Mecânica & $\begin{array}{c}\text { Bonjorno, Clinton, Eduardo Pardo } \\
\text { e Casemiro }\end{array}$ & $\begin{array}{l}3^{a} \text { edição } \\
\text { SP/2016 }\end{array}$ \\
\hline 5 & $\begin{array}{c}\text { Física - Termologia, Óptica, } \\
\text { Ondulatória }\end{array}$ & $\begin{array}{l}\text { Bonjorno, Clinton, Eduardo Pardo } \\
\text { e Casemiro }\end{array}$ & $\begin{array}{l}3^{\text {a }} \text { edição } \\
\text { SP/2016 }\end{array}$ \\
\hline 6 & $\begin{array}{l}\text { Física- Eletromagnetismo, Física } \\
\text { Moderna }\end{array}$ & $\begin{array}{c}\text { Bonjorno, Clinton, Eduardo Pardo } \\
\text { e Casemiro }\end{array}$ & $\begin{array}{l}\text { 3a edição } \\
\text { SP/2016 }\end{array}$ \\
\hline 7 & Ser protagonista - Físico $1^{\circ}$ ano & Edições SM & $\begin{array}{l}3^{\mathrm{a}} \text { edição } \\
\text { SP/2016 }\end{array}$ \\
\hline 8 & Ser protagonista - Físico $2^{\circ}$ ano & Edições SM & $\begin{array}{l}3^{\mathrm{a}} \text { edição } \\
\text { SP/2016 }\end{array}$ \\
\hline 9 & Ser protagonista - Físico $3^{\circ}$ ano & Edições SM & $\begin{array}{l}\text { 3a edição } \\
\text { SP/2016 }\end{array}$ \\
\hline 10 & $\begin{array}{c}\text { Física - Contexto e Aplicações - } 1^{\circ} \\
\text { ano }\end{array}$ & Máximo, Alvarenga e Guimarães & $\begin{array}{l}2^{\mathrm{a}} \text { ediç̧ão, } \\
\text { SP/2017 }\end{array}$ \\
\hline 11 & $\begin{array}{c}\text { Física - Contexto e Aplicações - } 2^{\circ} \\
\text { ano }\end{array}$ & Máximo, Alvarenga e Guimarães & $\begin{array}{l}2^{\mathrm{a}} \text { edição, } \\
\text { SP/2017 }\end{array}$ \\
\hline 12 & $\begin{array}{c}\text { Física - Contexto e Aplicações - } 3^{\circ} \\
\text { ano }\end{array}$ & Máximo, Alvarenga e Guimarães & $\begin{array}{l}2^{\mathrm{a}} \text { edição, } \\
\text { SP/2017 }\end{array}$ \\
\hline 13 & Física 1- Mecânica & Guimarães, Piqueira e Carron & $\begin{array}{l}2^{a} \text { edição } \\
\text { SP/2017 }\end{array}$ \\
\hline 14 & $\begin{array}{c}\text { Física } 2 \text {-Física Térmica, Ondas e } \\
\text { Óptica }\end{array}$ & Guimarães, Piqueira e Carron & $\begin{array}{l}2^{\mathrm{a}} \text { edição } \\
\text { SP/2017 }\end{array}$ \\
\hline 15 & $\begin{array}{c}\text { Física 3- Eletromagnetismo e Física } \\
\text { Moderna }\end{array}$ & Guimarães, Piqueira e Carron & $\begin{array}{l}2^{\mathrm{a}} \text { edição } \\
\text { SP/2017 }\end{array}$ \\
\hline 16 & Conexões com a Física 1 & Martini, Spinelli, Reis e Sant'Ana & $\begin{array}{l}3^{\text {a }} \text { edição } \\
\text { SP/ } 2016\end{array}$ \\
\hline 17 & Conexões com a Física 2 & Martini, Spinelli, Reis e Sant'Ana & $\begin{array}{l}\text { 3a edição } \\
\text { SP/ } 2016\end{array}$ \\
\hline 18 & Conexões com a Física 3 & Martini, Spinelli, Reis e Sant'Ana & $\begin{array}{l}\text { 3a edição } \\
\text { SP/ } 2016\end{array}$ \\
\hline 19 & Física em Contextos- $1^{\circ}$ ano & Andrade, Pietrocola, Pogibin e & $1^{a}$ edição \\
\hline
\end{tabular}

\footnotetext{
${ }^{3}$ A análise das nove coleções e não das doze aprovadas pelo PNLD refere-se ao fato de que tivemos acesso apenas as coleções apresentadas no Quadro 1.
} 


\begin{tabular}{|c|c|c|c|}
\hline & & Romero & SP/2016 \\
\hline 20 & Física em Contextos- $2^{\circ}$ ano & $\begin{array}{c}\text { Andrade, Pietrocola, Pogibin e } \\
\text { Romero }\end{array}$ & $\begin{array}{l}1^{a} \text { edição } \\
\text { SP/2016 }\end{array}$ \\
\hline 21 & Física em Contextos- $3^{\circ}$ ano & $\begin{array}{c}\text { Andrade, } \begin{array}{c}\text { Pietrocola, } \text { Pogibin e } \\
\text { Romero }\end{array}\end{array}$ & $\begin{array}{l}1^{\text {a }} \text { edição } \\
\text { SP/2016 }\end{array}$ \\
\hline 22 & Física 1- Mecânica & Helou, Gualter e Newton & $\begin{array}{l}\text { 3a edição } \\
\text { SP/2017 }\end{array}$ \\
\hline 23 & $\begin{array}{c}\text { Física 2- Termologia, Ondulatória e } \\
\text { Óptica }\end{array}$ & Helou, Gualter e Newton & $\begin{array}{l}3^{\text {a }} \text { edição } \\
\text { SP/2017 }\end{array}$ \\
\hline 24 & $\begin{array}{c}\text { Física 3- Eletricidade e Física Moderna } \\
\text { - Ciência e Tecnologia }\end{array}$ & Helou, Gualter e Newton & $\begin{array}{l}\text { 3a edição } \\
\text { SP/2017 }\end{array}$ \\
\hline 25 & $\begin{array}{c}\text { Termofísica, Óptica e Ondas -Ciência } \\
\text { e Tecnologia }\end{array}$ & Torres, Ferraro, Soares, Penteado & $\begin{array}{l}4^{a} \text { edição } \\
\text { SP/2016 }\end{array}$ \\
\hline 26 & $\begin{array}{c}\text { Eletromagnetismo e Física Moderna - } \\
\text { Ciência e Tecnologia }\end{array}$ & Torres, Ferraro, Soares, Penteado & $\begin{array}{l}4^{a} \text { edição } \\
\text { SP/2016 }\end{array}$ \\
\hline
\end{tabular}

Como recurso metodológico para análise dos livros didáticos utilizamos a Análise Textual Discursiva (ATD), conforme descrito por Moraes (2003). A ATD é considerada um "processo auto-organizado de construção de compreensão em que novos entendimentos emergem de uma sequência recursiva de três componentes": unitarização, categorização e a comunicação (p. 192). A unitarização, primeira etapa, é onde ocorre a desmontagem dos textos originais, unidades em que o analista irá atribuir "sentidos e significados" (p. 192). A categorização reúne elementos semelhantes buscando "[...] nomear e definir as categorias" (p. 197). E a comunicação, última etapa, é considerada o captar do "novo emergente", ou seja, momento em que novas compreensões e teorizações com relação aos fenômenos estudados são realizadas. Na ATD, a produção de categorias pode ser desenvolvida e construída a partir de diferentes métodos. No caso deste trabalho, utilizamos o método dedutivo, ou seja, que "implica construir categorias antes mesmo de examinar o 'corpus'" (MORAES; GALIAZZI, 2016, p. 45, grifo dos autores). Dessa forma, para a realização da análise dos livros didáticos tomamos como ponto de partida os três parâmetros orientadores da educação CTS e os diferentes níveis de criticidade desenvolvidos por Strieder e Kawamura (2017), portanto, categorias definidas a priori e que serão descritas e problematizadas a seguir.

\section{Resultados e discussão}

Conforme já exposto, o nosso corpus foi analisado considerando a matriz CTS apresentada por Strieder e Kawamura (2017) e que pode ser visualizada na figura 1. A análise considerou as cinco abordagens dos parâmetros CTS, ou seja, os cinco níveis de criticidade apresentados na racionalidade científica, desenvolvimento tecnológico e participação social. Assim, apresentamos a seguir os resultados encontrados visando sinalizar limitações e potencialidades com relação ao objetivo deste trabalho.

A racionalidade científica apresenta questões relacionadas à inserção da ciência no meio social, questões referentes ao método científico e este como propulsor do desenvolvimento (STRIEDER; KAWAMURA, 2017). Essas abordagens, quando vistas de maneira reducionista podem, de acordo com Auler (2002), apresentar uma perspectiva que alimenta visões supostamente neutras. Sendo assim, Strieder (2012) destaca a necessidade 
de um olhar crítico e problematizador sobre a racionalidade científica. Logo, apresentaremos a seguir às cinco abordagens que constituem esse e os outros parâmetros e a presença ou não nos livros didáticos e suas respectivas problematizações, conforme identificação apresentada na Tabela 1.

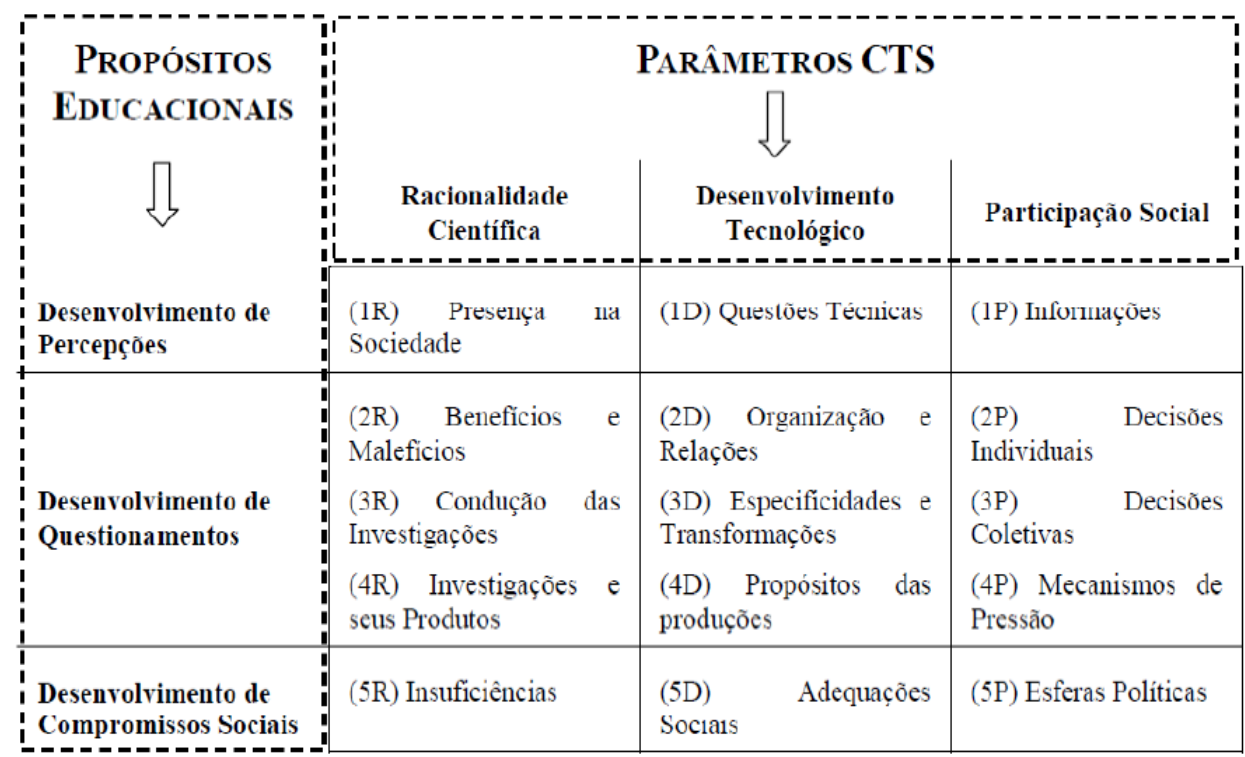

Figura 1 - Matriz CTS. Fonte: Strieder e Kawamura (2017, p. 49)

Tabela 1. Matriz de referência e presença nos livros didáticos.

\begin{tabular}{|c|c|c|c|}
\hline Parâmetros & Níveis de criticidade & Contempla (x) & Livros didáticos \\
\hline \multirow[t]{5}{*}{$\begin{array}{l}\text { Racionalidade } \\
\text { Científica }\end{array}$} & 1 & x & $\begin{array}{c}1,3,4,6,7,9,10,12,13 \\
14,16,18,19,20,21,22 \\
23,24,25,26\end{array}$ \\
\hline & 2 & $x$ & $\begin{array}{c}1,3,9,10,14,16,18,21,22 \\
26\end{array}$ \\
\hline & 3 & $x$ & 6 \\
\hline & 4 & $x$ & 3 \\
\hline & 5 & - & - \\
\hline \multirow{5}{*}{$\begin{array}{l}\text { Desenvolvimento } \\
\text { Tecnológico }\end{array}$} & 1 & $x$ & $\begin{array}{c}1,3,4,7,9,10,14,16,20 \\
21,26\end{array}$ \\
\hline & 2 & $x$ & $1,3,5,7,26$ \\
\hline & 3 & $x$ & 3 \\
\hline & 4 & $x$ & 26 \\
\hline & 5 & - & - \\
\hline \multirow{5}{*}{$\begin{array}{l}\text { Participação } \\
\text { Social }\end{array}$} & 1 & $x$ & $1,4,7,9,10,14,21,26$ \\
\hline & 2 & $x$ & 3,4 \\
\hline & 3 & $x$ & $1,7,9,10,26$ \\
\hline & 4 & - & - \\
\hline & 5 & - & - \\
\hline
\end{tabular}

O primeiro nível, denominado "1R - Explicitar a presença de ciência no mundo", tem como fundamento a perspectiva educacional de utilizar o conhecimento científico para explicar aspectos do cotidiano do estudante que envolvem ciência e tecnologia, em especial os relacionados aos produtos científicos usuais. Para as autoras (STRIEDER; KAWAMURA, 
2017), este nível apresenta, principalmente, a preocupação de evidenciar a importância do conhecimento científico para a compreensão do conteúdo/assunto estudado. Essa abordagem, conforme apresentado na tabela 1, se mostrou a mais frequente e presente nos livros didáticos. Esse número pode estar relacionado ao fato dessa perspectiva articular aspectos de ciência/física com discussões do cotidiano dos estudantes sendo, portanto, uma abordagem mais factível e acessível de discussões, porém não apresentam problematizações mais críticas sobre essas relações. Como exemplo desse nível, destacamos os livros 1, 3 e 4 que ao apresentarem o conteúdo referente às fontes de geração de energia apontam a energia elétrica como algo necessário e essencial à sociedade. Assim, por ser uma demanda social, é imprescindível pensar/discutir sobre sua produção. Logo, esses aspectos evidenciam aproximações com o nível $1 \mathrm{R}$ da racionalidade científica porque apresentam o conhecimento científico como ferramenta para que o estudante tenha o entendimento de um conteúdo que traz implicações cotidianas, no entanto não avança para as questões sociais e ambientais. Nesse sentido, podemos situar as discussões presentes nos livros didáticos que evidenciam a produção de energia elétrica por meio de fontes alternativas e renováveis. Nos livros 1 e 4, por exemplo, há explicitações e exemplificações dessas questões, já no livro 3 tem-se discussões referentes a necessidade do uso consciente da energia a partir de uma análise da conta de energia elétrica. Contudo, essas questões não abordam dimensões para além de uma inserção e aproximação com o cotidiano. Ou seja, não há um diálogo com dimensões políticas, socioeconômicos e ambientais de maneira problematizadora.

Os exemplos apresentados permitem articulações do conteúdo estudado com aspectos do cotidiano que envolvem ciência e tecnologia, mas se limitam no alcance de propósitos CTS mais amplos, como o de questionamento e compromisso social (STRIEDER; KAWAMURA, 2017). Se o objetivo educacional CTS está na formação de sujeitos críticos e atuantes em questões socioambientais, econômicas e culturais, o nível 1R é limitante, pois precisamos ir além da linearidade ciência e sociedade, de conhecimentos pautados apenas pela dimensão técnico-científica e disciplinar. Para o alcance desse objetivo e propósitos mais amplos CTS, é necessário que o trabalho com temas socioambientais que envolvam ciência e tecnologia sejam pautados pela "complexidade que a conformam", por "valores, interesses, objetivos, posicionamento ético e político e contradições [...] que busca imprimir uma educação científica para o desenvolvimento sustentável" (VASCONCELOS; FREITAS, 2012, p. 104). A nosso ver, os livros que incorporam apenas os primeiros níveis da matriz são limitantes nesse sentido, cabendo, dessa forma, ao professor potencializar e articular essas discussões no processo educacional.

O nível "2R - Discutir malefícios e benefícios dos produtos da ciência" apresenta o questionamento acerca do uso dos produtos da ciência. Ou seja, essa perspectiva se associa a avaliação dos produtos, positivo ou negativo, a partir do uso que os sujeitos fazem dele. Um exemplo dessa perspectiva está presente no livro 3 ao discutir as usinas termoelétricas e os benefícios e malefícios oriundos dela. A ideia apresentada no livro está no fato de que a geração de energia dessa usina seria mais apropriada e proveitosa em tempos de estiagem, quando a produção de energia em hidrelétricas pode não atender as demandas necessárias. Além do exposto, o livro discute a ideia de que apesar de ser uma forma de geração de energia de baixo custo, a energia gerada em termoelétricas provoca muitos impactos ambientais. Na tabela 1 podemos notar que esse nível também é muito presente nos livros analisados. Atribuímos isso ao fato do olhar da sociedade, em linhas gerais, ao 
que diferentes autores têm denominado de cultura de avaliação pós-produção, ou seja, uma tendência em avaliar os impactos, negativos e positivos, dos produtos oriundos da ciência e tecnologia, mas sem problematizar os aspectos valorativos que influenciam a escolha e condução de determinados direcionamentos e políticas científico-tecnológicas. É válido ressaltar que essa perspectiva, de avaliação pós-produção, tem sido evidenciada e trabalhada em muitas práticas educativas CTS (AULER, 2011; ROSA; AULER, 2016; SANTOS; AULER, 2019).

A perspectiva "3R - Analisar as conduções da investigação científica" problematiza o desenvolvimento científico com o intuito de questionar as construções históricas e filosóficas, desmistificando-a como verdade absoluta e questionando sua suposta neutralidade. Entende-se a ciência como um processo sujeito a fatores humanos e sociais, pois ela é vista como construção humana estando assim imersa a influências sociais. Nossa análise evidenciou a pouca presença desse nível nos livros didáticos. O livro 6, por exemplo, conseguiu, de alguma maneira, propor discussões desse nível, em especial por trazer aspectos referentes ao uso da eletricidade em procedimentos da medicina em diferentes épocas, destacando os diversos mitos sobre o seu uso, possibilitando aspectos históricos e filosóficos da ciência, em especial questionamentos sobre a sua suposta neutralidade. Ao decorrer da discussão, o livro ressalta que "[...] na falta de verdade absoluta, resta-nos estudar e tentar compreender a utilização dessas ideias em seu próprio contexto" (LIVRO 6, p. 14). O fato da pouca presença dessa perspectiva nos livros pode estar associado à necessidade de um estudo mais robusto da história e natureza da ciência, aspectos que podem contribuir para a desmistificação de visões reducionistas dela. É válido ressaltar que nosso estudo se reduziu as abordagens trabalhadas sobre tópicos que envolvem questões energéticas, logo é possível que na discussão de outros objetos de conhecimento os livros possam apresentar mais proposições referentes aos diferentes níveis de criticidade.

O nível "4R - Questionar as relações entre investigação científica e seus produtos" reconhece que a racionalidade científica responde a interesses de certos grupos sociais, incluindo aspectos de influências econômicas, políticas e sociais. Para as autoras, nas práticas CTS pode-se trazer discussões sobre os rumos das pesquisas científicas, a definição das agendas de pesquisa e os investimentos privilegiados em uma dada área. No livro 3 identificamos, por exemplo, o fato da explicitação da trajetória da Física no Brasil ao abordarem o pouco investimento em pesquisas em diferentes épocas. No entanto, não há uma discussão aprofundada no assunto, trazendo em síntese apenas uma discussão histórica, portanto, a nosso ver, contemplando superficialmente às discussões do " $4 \mathrm{R}$ ".

O nível "5R - Abordar a insuficiência da ciência" situa a ciência como um conhecimento que, apesar de atender certas demandas da sociedade, não é capaz de explicar sozinha a complexidade do mundo e dos problemas contemporâneos. Portanto, aponta para a necessidade de diálogos com outros saberes, experiências, práticas que não necessariamente encontram-se na ciência e na tecnologia. Essa abordagem não foi identificada, de maneira explícita, nos livros. Fato que aponta para a necessidade da reflexão sobre aspectos mais críticos sobre a educação CTS, sua complexidade e como articulá-las às práticas e materiais educativos.

O parâmetro que discute o desenvolvimento tecnológico visa problematizações referentes à ciência e tecnologia, especificidades do conhecimento tecnológico e suas relações sociais. O primeiro nível, "1D - Abordar questões técnicas", busca a compreensão das questões técnicas dos produtos científico-tecnológicos como, por exemplo, entender 
como funciona as partes ou equipamentos de um produto e o que é necessário para ele funcionar. Um exemplo evidenciado no livro 9 refere-se às discussões sobre os tipos de lâmpadas (LEDs, fluorescentes e incandescentes), destacando qual lâmpada gasta menos energia elétrica, ou seja, qual é mais eficiente, apresentando discussões sobre qual seria a melhor escolha e explicando os motivos de acordo com os conhecimentos técnicocientíficos.

A perspectiva "2D - Analisar organizações e relações entre aparato e sociedade" apresenta problematizações sobre essas relações tomando como base o produto e o reconhecimento da necessidade de recursos humanos para o seu desenvolvimento e funcionamento. Nessa perspectiva, há também relações entre o aparato ser avaliado como positivo ou negativo. No livro 1 é dado o exemplo da energia eólica abordando os recursos (sociais e ambientais) necessários para sua implementação. É destacado ainda que mesmo sendo uma fonte de energia sustentável, ainda tem potencial de gerar implicações negativas como a poluição sonora sendo, portanto, uma matriz energética que também tem implicações socioambientais embora em menor escala quando comparada com outras. É válido ressaltar que nessa perspectiva as implicações sociais e ambientais oriundas do uso dos produtos científico-tecnológicos são reconhecidas e não necessariamente passíveis de críticas e problematizações mais profundas.

O nível "3D - Discutir especificidades as transformações acarretadas pelo desenvolvimento tecnológico" considera a tecnologia como não decorrente, diretamente, da ciência, e o fato de que ela sofre influência social na sua concepção e condução. No contexto educacional, por exemplo, pode-se analisar os fatores de implementação e as mudanças acarretadas em determinado lugar/região devido a implementação de uma usina, ou as mudanças que as usinas já implementadas causaram. Na nossa análise, percebemos no livro 3 aspectos coerentes com esse nível ao evidenciar discussões sobre a grande produção de lixo eletrônico. A abordagem problematiza o fato de que grande parte dos produtos que geram lixo eletrônico estão associados ao mercado/sistema capitalista que estimulam o consumo, ou seja, há a implicação/influência social nesse problema. Em outras palavras, o sistema capitalista fez com que houvesse, cada vez mais, o aumento de produção de aparatos tecnológicos que são facilmente substituídos e que acabam implicando, consequentemente, no aumento do consumo e descarte. No livro, é evidenciado o fato de que essas implicações acontecem, também, em outros setores, como a moda, discussões de extrema relevância para se problematizar o consumo exacerbado, obsolescência planejada, lixos produzidos, entre outras questões.

O nível "4D - Questionar os propósitos que tem guiado a produção de novas tecnologias" tem sua ênfase para as discussões que problematizam a ideia de que "o desenvolvimento seguido nos últimos séculos é o melhor possível e de que ele é o resultado direto do conhecimento científico" (STRIEDER; KAWAMURA, 2017, p. 38). Logo, a tecnologia é vista como uma "estrutura cultural que inclui valores", ou seja, ela deixa de ser vista como neutra e é um sistema que afeta a vida em sociedade. Essa perspectiva, foi de maneira geral e superficial observada no livro 26 ao propor às discussões referentes aos impactos que as construções de diversas usinas para geração de energia elétrica podem causar, tais como poluição atmosférica, mudanças ambientais irreversíveis ou até mesmo riscos de acidentes nuclear no caso das usinas nucleares. Logo, de alguma maneira, essas discussões podem permitir a problematizações de aspectos antecedentes e que influenciam a escolha por determinados direcionamentos científico-tecnológicos, investimentos e definições para 
agendas de pesquisa. Em outras palavras: "O que está implícito; o que está por trás das forças políticas e sociais que orientam o desenvolvimento" (STRIEDER; KAWAMURA, 2017, p. 39).

Por fim, o nível "5D - Discutir a necessidade de adequações sociais" compreende a importância de adequações sociais da tecnologia, buscando a construção de tecnologia baseado no sistema cultural, econômico, político e social para suprir as necessidades e problemas de determinada população. Essa abordagem é o que mais se aproxima dos propósitos defendidos pelo PLACTS. No entanto, assim como no 5R, o 5D também não foi percebido/identificado, explicitamente, nos livros didáticos. Ressaltamos que, dentre outros aspectos, poderia ser apresentado discussões referentes à qual matriz energética melhor se adequa as diferentes realidades brasileiras e em termos de um desenvolvimento social e ambiental mais sustentáveis? Ou ainda, como as políticas públicas estão direcionadas as diferentes realidades e demandas brasileiras sobre esse tema?

Referente à participação social destaca-se o desenvolvimento de decisões e direcionamentos de políticas públicas sobre temas que envolvem ciência e tecnologia determinadas não só por cientistas, mas também por diversos grupos sociais que carregam valores, intencionalidades e demandas diferentes. Esse parâmetro contribui para desconstruir a percepção de decisões unicamente tecnocráticas colocando em pauta processos democráticos em torno da ciência e tecnologia. O nível "1P - Adquirir informações e reconhecer o tema e suas relações com a ciência e a tecnologia" está associado a ideia de que a sociedade precisar estar informada sobre os avanços relacionados à ciência e tecnologia. Logo, busca-se uma aproximação maior da sociedade com esses temas. Na nossa análise, destacamos o livro 10 por apresentar discussões envolvendo investigações sobre o desenvolvimento sustentável através dos avanços da ciência e tecnologia como, por exemplo, o investimento em fontes de geração de energia mais sustentáveis, o estímulo de um uso mais sustentável dos recursos naturais e investimentos em pesquisas nessa área. Assim como nos dois últimos parâmetros analisados, este nível de abordagem foi, também, o mais presente nos livros.

O nível "2P - Avaliar pontos negativos e positivos relacionados ao tema" refere-se a discussões que envolvem decisões individuais e situações específicas. Este nível está fundamentado na participação a partir da avaliação dos pontos negativos e positivos sobre o uso de determinados produtos científico-tecnológicos, podendo provocar reflexão e mudanças de atitudes de cunho individual como, por exemplo, a discussão sobre uso adequado da água. Sobre este nível, destacamos novamente as inserções relacionadas a produção de lixo eletrônico tratadas no livro 3. Neste, há o destaque para o fato de que o consumo excessivo e a falta de conhecimento sobre os problemas socioambientais envolvendo o lixo eletrônico fazem com que aumente a produção e o descarte incorreto dele. Percebemos, portanto, que o livro potencializa discussões sobre a importância do envolvimento da população em adquirir conhecimentos sobre esse tema (1P), além do fato de que esse conhecimento pode possibilitar os sujeitos de avaliarem de maneira positiva ou negativa, fazendo um bom ou mau uso do produto (2P).

O nível "3P- Discutir problemas, impactos e transformações sociais da ciência e da tecnologia" envolve discussões sobre decisões coletivas e tem o reconhecimento das transformações sociais causadas pelo desenvolvimento da ciência e da tecnologia buscando a compreensão de sua aplicação em diferentes contextos. Diferente do anterior, este nível não tem como pretensão apenas avaliar aspectos positivos e negativos, mas problematizar 
sobre as implicações em diferentes contextos como analisar "transformações pelas quais a sociedade tem passado em virtude do uso do celular, do computador ou de organismos geneticamente modificados" (STRIEDER; KAWAMURA, 2017, p. 40). Essa abordagem foi identificada no livro 7, em específico quando os autores discutem/propõe problematizações acerca da dependência social da energia, e como ela foi inserida na sociedade de tal forma que hoje se tornou essencial.

A abordagem "4P - Identificar contradições e estabelecer mecanismos de pressão" tem sua ênfase para a compreensão de fatores políticos e suas influências no desenvolvimento científico-tecnológico. Em outras palavras, este nível envolve a relação de poder existente nesse meio. Para Strieder e Kawamura (2017), nas práticas CTS é possível trabalhar com o estudo de implementação de uma fábrica, buscando entender os trâmites políticos de cada ação, das relações de poder e contradições envolvidas. Já o nível "5P - Compreender políticas públicas e participar no âmbito das esferas políticas" visa discutir questões que envolvem os conhecimentos e produtos referentes à ciência e tecnologia que ainda não foram estabelecidos. Nesse sentido, busca-se ampliar a participação social nas decisões sobre esses direcionamentos, gerando interação e negociação entre a sociedade em geral e os cientistas na política científico-tecnológica. No âmbito educacional, este nível pode ser trabalhado quando temas/problemas de contradições sociais que abordam ciência e tecnologia, ainda não estabelecidos, são tratados em termos de direcionamentos e decisões que incluem fatores políticos/sociais. Nesta perspectiva, há a possibilidade de exercitar processos de tomadas de decisões ampliados sobre temas sociais de ciência e tecnologia. É válido destacar, no entanto, que na nossa análise não identificamos elementos de discussão e problematização referentes aos níveis 4P e 5P.

\section{Considerações finais}

Conforme destacamos inicialmente, no Ensino de Ciências/Física há diferentes desafios a serem enfrentados. Assim, neste trabalho, destacamos àqueles que envolvem, principalmente, perspectivas educacionais articuladas com propósitos que buscam a formação de sujeitos críticos e reflexivos frente a temas sociais articulados com a nossa área. Das demandas que envolvem essa constituição, ressaltamos a problematização e redirecionamentos dos currículos escolares, práticas e materiais educativos. Dessa forma, compreendendo que o campo de pesquisas CTS tem como um dos seus objetivos educacionais propor trabalhos em torno de temáticas interdisciplinares e que envolvem a constituição de processos de democratização da ciência e tecnologia (SOUZA, 2012), propomos analisar como os livros didáticos de Física, aprovados no PNLD 2018, apresentam limitações e potencialidades em torno de perspectivas críticas desse campo, tendo em vista que os livros didáticos são considerados um dos principais materiais para a elaboração e planejamento de propostas curriculares e de práticas educativas.

Nesse sentido, como resultado da nossa análise, destacamos o fato de que, conforme o nível de cada parâmetro da matriz de referência aumenta, o que se percebe é uma diminuição de aspectos potencializadores que permitem/indiquem 0 trabalho e a problematização nos livros didáticos. Além disso, é válido destacar também que os níveis de criticidade não são identificados de maneira linear. Em outras palavras, muitos livros didáticos apresentam aspectos que contemplam alguns níveis de um dado parâmetro, como o dois e quatro, e não necessariamente o um, depois o dois e o três. Ou seja, 
percebe-se que os diferentes níveis de criticidade não são, necessariamente, identificados e contemplados de uma forma progressiva. Aspectos já problematizados por Strieder e Kawamura (2017) em seus estudos.

Além do exposto, chamamos a atenção para o fato de que, embora tenha sido identificado diferentes parâmetros CTS nos livros didáticos, a presença dessas discussões/atividades/problematizações se encontra, principalmente, em propostas isoladas, especialmente, no início ou final dos capítulos, como curiosidade ou como atividade complementar. Embora essas discussões possibilitem que os professores ampliem e potencializem propósitos CTS, esse fato pode levar, também, a uma não inclusão e problematização no trabalho didático-pedagógico do professor, já que, de maneira geral, as inclusões estão desarticuladas da exposição do conteúdo científico. Logo, sua inserção na prática pode ficar fragilizada. Aspecto que poderia ser modificado e/ou potencializado, por exemplo, com a inclusão delas ao longo da apresentação e discussão dos objetos de conhecimento da Física, aspecto observado, mais potencialmente, na primeira coleção. Por fim, destacamos que embora os livros didáticos apresentem poucos tópicos que contemplem os últimos níveis dos parâmetros CTS, ressaltamos a presença de diferentes questões referentes aos outros níveis nos livros didáticos, aspecto importante para a área, pois indica algumas possibilidades de trabalho voltados para a educação CTS.

Como encaminhamento final, destacamos resultados importantes para o Ensino de Ciências/Física, visto que possibilitou, além da análise dos livros didáticos, discutir e indicar, de maneira crítico-reflexivo, possibilidades de trabalho sobre temas sociais que envolvem ciência e tecnologia, em especial suas articulações com questões energéticas. Discussões relevantes para a área, principalmente quando o propósito é a formação crítica, motivadora e significativa para os estudantes, pois os temas partem de aspectos da realidade vivida e visam à construção de pensamento crítico, ações e atuação na sociedade, mesmo que em diferentes níveis de criticidade.

\section{Referências}

AULER, D. Articulação Entre Pressupostos do Educador Paulo Freire do Movimento CTS: Novos Caminhos Para a Educação em Ciências, Contexto e Educação, v. 22, n. 77, p. 167-188, 2007.

AULER, D. BAZZO, W. A. Reflexões para a implementação do movimento CTS no contexto educacional brasileiro, Ciência \& Educação, v.7, n 1, p. 1-13, 2001.

AULER, D. Interações entre Ciência-Tecnologia-Sociedade no Contexto da Formação de

Professores de Ciências. 2002. Tese (Doutorado em Educação), Centro de Educação, Universidade Federal de Santa Catarina, Florianópolis, 2002.

AULER, D. Novos caminhos para a educação CTS: ampliando a participação. Em SANTOS, W. L. P.; AULER, D. (Org.). CTS e educação científica: desafios, tendências e resultados de pesquisas. Brasília: Universidade de Brasília, 2011, p. 73-98.

BRASIL. Ministérios da Educação. Edital de convocação para o processo de inscrição e avaliação de obras didáticas para o Programa Nacional do Livro Didático. Brasília, 2015. Disponível em: https://www.fnde.gov.br/programas/libro-didatico/livro-didatico-editais. Acesso em 11 de jul. 2018.

BRASIL. Programa Nacional do Livro e do Material Didático: apresentação. Disponível em: https://portal.mec.gov.br/pnld/apresentacao. Acesso em: 01 ago. 2019. 
FREIRE, P. Pedagogia do Oprimido. 48. ed. Rio de Janeiro: Paz e Terra, 2005.

GARCÍA, M. G.; CEREZO, J. A. L.; LÓPEZ, J. L. L. Ciencia, Tecnologia Y Sociedad: una introducción al estudio social de la Ciência y la tecnología. Madrid: Tecnos, 1996.

HUNSCHE, S. Professor fazedor de currículos: desafios do estágio curricular supervisionado em Ensino de Física. 2010. 144f. Dissertação (Mestrado em Educação). Universidade Federal de Santa Maria, Santa Maria, 2010.

MORAES, R. Uma tempestade de luz: a compreensão possibilitada pela análise textual discursiva. Ciência \& Educação, Bauru, v.9, n.2, p.191-211, 2003.

MORAES; GALIAZZI. Análise Textual Discursiva. ljuí: Editora Unijuí, 2016.

MOREIRA, M. A. Desafios no ensino da física. Revista Brasileira de Ensino de Física, v. 43, n. 1, p. 1 8, 2021.

MOREIRA, M. A. Uma análise crítica do ensino de Física. Estudos avançados, v. 32, n. 94, p. 73-80, 2018.

RIBAS, J. F.; BROIETTI, F. C. D. Um estudo da produção escrita de estudantes do Ensino Médio em questões de Ciências do PISA. Amazônia - Revista de Educação em Ciências e em Matemática, Belém, v. 16, n. 36, p. 244-262, 2020.

ROSA, S. E. Educação CTS: contribuições para a constituição de culturas de participação. 2019. 280f. Tese (Doutorado em Educação em ciências). Universidade de Brasília, Brasília, 2019.

ROSA, S. E.; AULER, D. Não Neutralidade da Ciência-Tecnologia: Problematizando Silenciamentos em Práticas Educativas Relacionadas à CTS. Alexandria Revista de Educação em Ciência e Tecnologia, Florianópolis, v. 9, n. 2, p. 202-231, nov, 2016.

SANTOS, W. L. P dos. Educação CTS e cidadania: confluências e diferenças. Amazônia - Revista de Educação em Ciências e em Matemática, Belém, v. 9, n. 17, p. 49-62, jul, 2012.

SANTOS, R.; AULER, D. Práticas educativas CTS: busca de uma participação social para além da avaliação de impactos da Ciência-Tecnologia na Sociedade. Ciência \& Educação, Bauru, v. 25, n.

2. p. $485-503$.

SOUZA, F. Uma contribuição teórica da utilização da abordagem CTS no Ensino de Ciências. Amazônia - Revista de Educação em Ciências e Matemáticas, Belém, v.9, n, 17, p. 109 - 121, jul, 2012.

STRIEDER, R. Abordagem CTS na Educação Científica no Brasil: Sentidos e Perspectivas. 2012. Tese (Doutorado em Ensino de Ciências), Instituto de Física, Universidade de São Paulo, São Paulo, 2012.

STRIEDER, R.; KAWAMURA, M. Educação CTS: Parâmetros e propósitos brasileiros, Alexandria Revista de Educação em Ciência e Tecnologia, v. 10, no 1, p. 27-56, 2017.

VASCONCELOS, E.; FREITAS, N. O paradigma da sustentabilidade e a abordagem CTS: mediações para o Ensino de Ciências. Amazônia - Revista de Educação em Ciências e Matemáticas, Belém, v.9, n, 17, p. $89-108$, jul, 2012.

VON LINSINGEN, I. Perspectiva educacional CTS: aspectos de um campo em consolidação na América Latina. Ciência \& Ensino, v. 1, n. especial, nov. de 2007. 